\title{
VALIDATION OF TORSIONAL RIGIDITY OF FSAE CHASSIS
}

\section{DEVESH ANAND, ANUJ GUPTA \& JEYANTHI SUBRAMANIAN}

Department of Mechanical Engineering, School of Mechanical and Building Sciences

VIT, Chennai, Tamil Nadu, India

\section{ABSTRACT}

The aim of this paper is to study the torsional stiffness of FSAE space frame chassis by FEA and experimental testing. The chassis is the skeleton of the car which holds all other components. Torsional forces are experienced by the chassis when a foreign object comes below any one of the tyres, although the forces are damped by the dampers connected to the A-arms, and the anti-roll bar, the chassis experiences the torsional forces through the hard points (suspension mounting points). Torsional forces are also experienced when the car is taking a turn. The chassis was designed by Shaurya Racing following the rules of Formula Bharat 2018. The chassis was designed for maximum strength and minimum weight which can withstand all the static and dynamic loads. The AISI1026 chassis weighs $25 \mathrm{Kgs}$ (without any brackets) which is $8 \mathrm{Kgs}$ lesser than the 2017 chassis. The jig for testing was designed for lesser cost and easier manufacturing. The FEA results of torsional rigidity were compared to the experimental values. The same test is done repeatedly at the same point with different loads to eliminate errors in the experiment.

KEYWORDS: FSAE, Torsional Rigidity, Formula Bharat, Chassis, Chassis Testing, FEA Validation, Formula Student \& Torsion Testing

Received: Aug 22, 2018; Accepted: Sep 12, 2018; Published: Oct 29, 2018; Paper Id.: IJMPERDDEC201826

\section{INTRODUCTION}

Formula Bharat is a national student-level mechanical design competition held in Coimbatore India, we were ranked $12^{\text {th }}$ out of 71 teams which participated this year. Several types of frames are used in formula student and the most popular ones are space frame, monocoque and ladder frame chassis. Our chassis is single piece space frame because of lightweight, easy manufacturability and less cost [1]. The chassis is for an open cockpit singleseater racing car with 4 wheels that are not in a straight line [2]. The chassis is triangulated at all the nodes for good transmission of forces. The twisting force along the Z- direction is a torsional force. Usually, FSAE chassis has a torsional stiffness of $1500 \mathrm{Nm} /$ degrees [3]. FEA is not 100 percent correct because of errors in manufacturing and data of the material fed in the software and localized changes in the material because of external factors like heat affected zone from welding, so the need of physical testing arises. In the recent times, validation of design is very important and is given high importance in competitions and industrial applications. If we consider a $100 \%$ rigid chassis, then the spring damper and anti-roll bars bear all the load [4]. When the load is applied on one side of the chassis, then the side of load application deflects downwards and the other side deflects upwards, the deflection is measured by a dial gauge at varying loads that is varying torque and many readings are taken at a single point to eliminate errors in the experiment. In some experiments done by other researchers the difference of deflections at both the ends to get deflection only by rotation [5]. But in our experiment to restrict the other deflection we have included an extra support in our jig. Torsional stiffness does not affect the lateral acceleration of the car, yaw and other properties at steady state turns [6]. 
The total stiffness of the chassis can be found out by $\frac{1}{K}=\frac{1}{\mathrm{k} \text { (Front) }}+\frac{1}{\mathrm{k}(\text { Cockpit })}+\frac{1}{\mathrm{k}(\text { Rear })}$ [7], the stiffness of the cockpit is an important component as safety comes first. Torsional forces are experienced by the chassis because of suspension systems. If the chassis is not stiff enough, it will bend along its Z- axis and if the chassis bends because of the torsional load it will affect the suspension system thus torsional stiffness is important for dynamic conditions of the car [8]. There is one benefit of a less stiff chassis as it will transfer weight between front and rear tyres, but this deviates from the calculations made for the vehicle dynamics and there is not much proof of weight distribution, thus a less stiff chassis is not preferred [9].

\section{METHODOLOGY}

In the below figure consider the triangle $\mathrm{ABC}, \mathrm{A}$ is the point on the chassis where the deflection is measured, $\mathrm{B}$ is the deflected point on the chassis after the load is applied. $\mathrm{C}$ is the center of rotation which lies on the $\mathrm{Z}$-axis. So $\mathrm{AB}=$ deflection ' $\mathrm{d}$ ', $\mathrm{BC}$ is the distance of load application point from the center of rotation so $\mathrm{BC}=335 \mathrm{~mm}$ in our case.

From figure $1, \sin (\alpha)=\frac{A B}{B C}=\frac{d}{335}$

Therefore, $\alpha=\sin ^{-1} \frac{d}{335}$

For calculating the angle of twist some papers have used tan inverse of length/deflection [5] but we will but using sin inverse in our formula for more accurate results as the distance known to us is the hypotenuse and deflection, using sin inverse in our formula will not create much difference as sin and tan are almost same for small angles. FSAE chassis are strong enough to bear large torsional loads so any kind of bending during the experiment or realtime running will not create any damage to it [10].

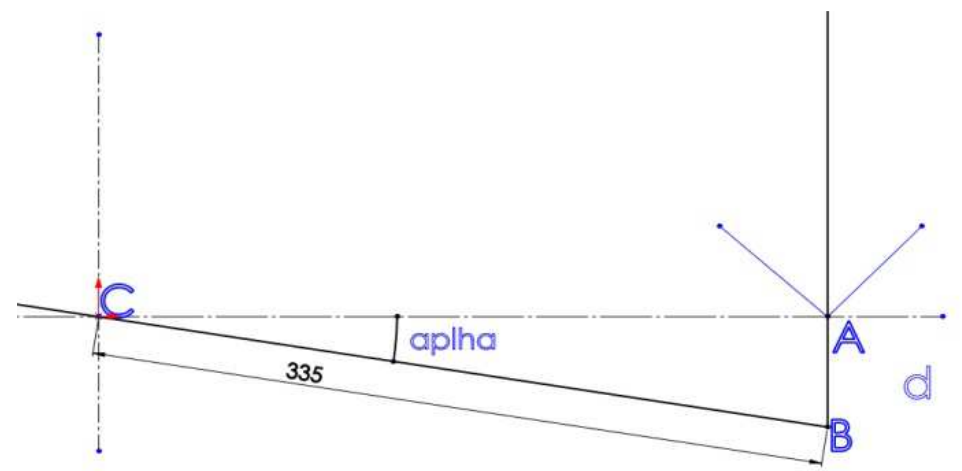

Figure 1: Angle of Twist, $\alpha$

A jig was designed to fix the rear hard points and torque was applied through the front hard points. A dial gauge is used to measure the deflection. The jigs are designed in a way that it does not leave any gap in between the chassis tubes and the jig plates, it was taken care that the brackets in the chassis don't interfere with the jigs and if interference is there, a slot was made on the jig. The height of the jig was decided considering the height of the dial gauge so that the dial gauge can be easily kept below the chassis. The holes are made of $8.1 \mathrm{~mm}$ diameter for easy sliding of bolts through it and the position of the holes are made in such a way that there is a bolt between any 2 tubes of the hard points to ensure enough rigidity. The number of bolts is kept more than required as the rear of the chassis should not move in the jig when the load is applied if there is any deflection in any axis in the rear part because of the load the values in the dial gauge will not be correct. 

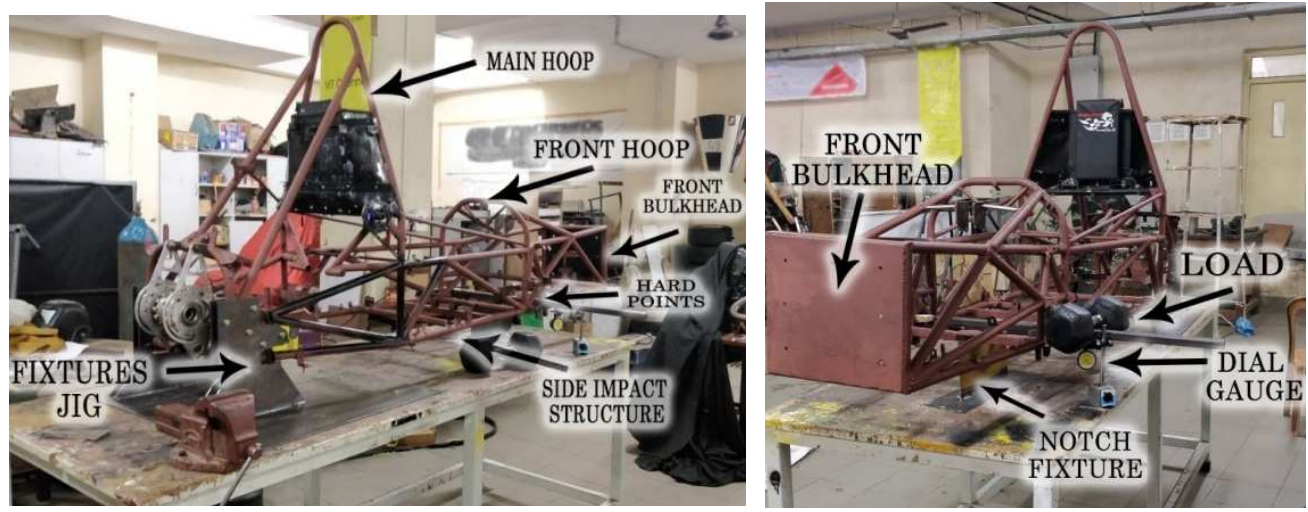

Figure 2: General Terms of a Chassis

The jigs are made of $5 \mathrm{~mm}$ MS sheet so that it does not bend when the load is applied and was manufactured by laser cutting and welded to a $5 \mathrm{~mm}$ MS base using TIG welding.

The 2 plates of the jigs fixtures were taken and the plates were bolted on the chassis using M8 bolts of 3-inch length, nylon lock nuts, and washers. The nuts were tightened to the maximum possible limit on both the rear hard points. The base was separately mounted on a rigid table using M8 bolts of 3-inch length, nylon lock nuts, and washers. The plates which are tightly bolted on the chassis are now strongly welded to the base as shown in figure 2 .

The torsional load is applied through the front hard points. A T-shaped structure is made using a1-inch square tube of $3 \mathrm{~mm}$ thickness and the trunk of the $\mathrm{T}$ passes through the hard points. A square tube is used, as a round tube will roll when the load is applied. A rectangular wooden block is kept between the square tube and the vertical tube connecting 2 hard points so that there is no space for the square tube to slide when the load is applied as shown in figure 2.

The test was conducted using the jig and then it was found that the chassis was bending about the Z-axis (as shown in Figure 3). This was concluded by measuring the deflection on both the sides. As if there was deflection only because of torsion the magnitude of deflection will be same on both sides of load application.

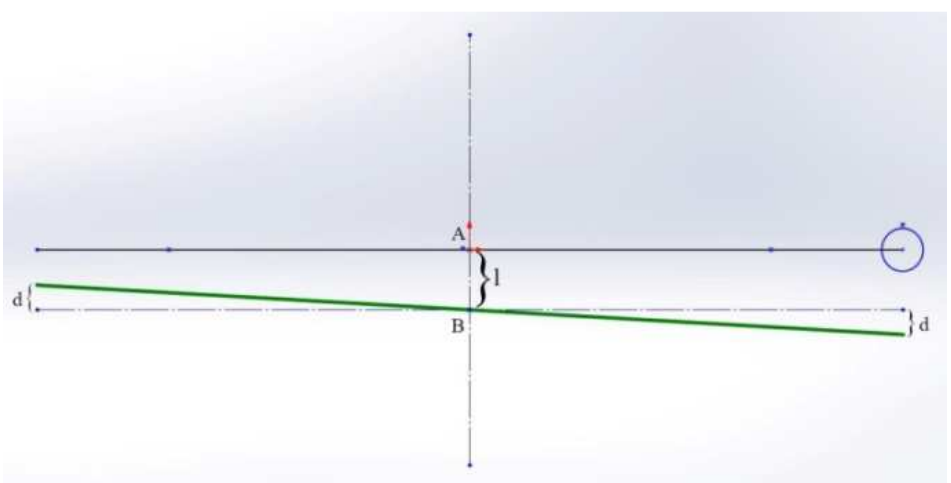

Figure 3: Deflection about $\mathrm{Z}-$ axis

Figure 3 shows the front hard points in the front view when bending along the Z- axis is there.

A is the mid-point of the line connecting the 2 front points

$\mathrm{B}$ is the mid-point of the line connecting the 2 front points after bending about $\mathrm{Z}$ - axis.

Thus the distance $\mathrm{AB}=\mathrm{L}$ is a deflection in the chassis because of bending along its $\mathrm{Z}$ - axis. So advancement in the jig design was done to eliminate this deflection due to bending as shown in Figure 2 (notch Fixture). For this a flat plate 
with a notch was kept below the front hoop in the center of the chassis, this will only restrict bending about Z- axis and will create no errors in the deflection due to torque as there will be no deflection at the center of rotation of the chassis because of the torque.

\section{Finite Element Analysis}

Software used- Solid Works

Model- Static Structural

Boundary Conditions- the rear 8 hard points were fixed.

Load- $12.5 \mathrm{~kg}, 15.5 \mathrm{~kg}, 18.5 \mathrm{~kg}, 21.5 \mathrm{~kg}, 25.5 \mathrm{~kg}$ load it applied in the negative $\mathrm{Y}$ direction at the end of the $\mathrm{t}$ shaped square tube.

Observation- Deflection is measured at the desired 4 points using a probe, in degrees with respect to the $\mathrm{X}$ direction.

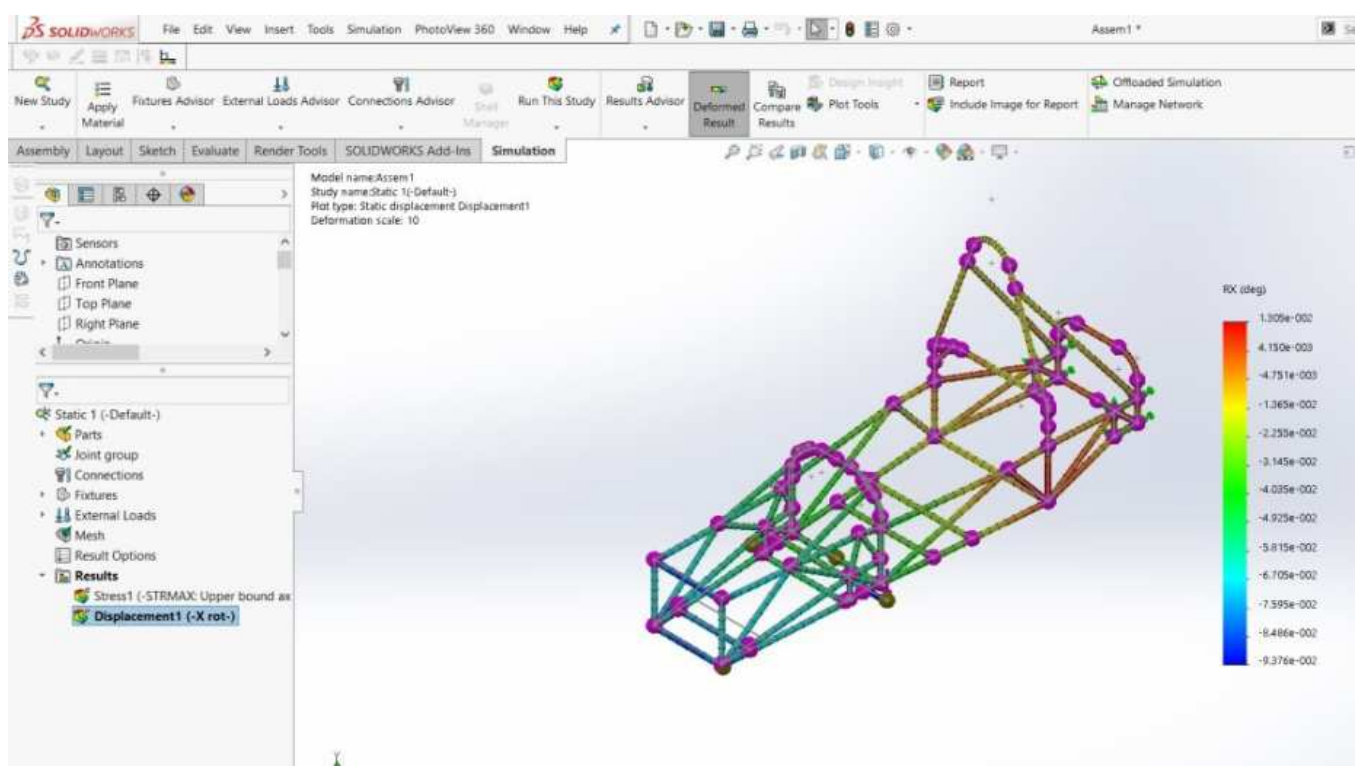

Figure 4: Finite Element Analysis

\section{Calculation}

Angle of twist $(\varphi)=\sin ^{-1} \frac{d}{L}$

Where $d=$ deflection $\mathrm{k}_{\mathrm{f}}$

$\mathrm{L}=$ distance of load application point from the centre of the chassis

Torque $(\mathrm{T})=\mathrm{mgL}$

Torsional rigidity $=\frac{T}{\varphi}$

Average torsional stiffness of the chassis

$\frac{1}{K}=\frac{1}{\mathrm{k}(\text { Front })}+\frac{1}{\mathrm{k}(\text { Cockpit })}+\frac{1}{\mathrm{k}(\text { Rear })}$ 


\section{RESULTS AND DISCUSSIONS}

Table 1: Deflection is Measured at a Point Which is $310 \mathrm{~mm}$ from the Front Bulkhead

\begin{tabular}{|c|c|c|c|c|c|c|c|c|}
\hline $\begin{array}{c}\text { Load } \\
\text { (kg) }\end{array}$ & $\begin{array}{c}\text { Deflection } \\
(\mathbf{m m})\end{array}$ & $\begin{array}{c}\text { Angle of Twist } \\
\text { Taking } \\
\text { L=355mm } \\
\text { (degrees) }\end{array}$ & $\begin{array}{l}\text { Toque } \\
\text { Applied } \\
\text { (Nm) }\end{array}$ & $\begin{array}{l}\text { Torsional } \\
\text { Rigidity } \\
\text { (Nm/deg) }\end{array}$ & $\begin{array}{c}\text { Average } \\
\text { Torsional } \\
\text { Rigidity } \\
(\mathrm{Nm} / \mathrm{mm})\end{array}$ & $\begin{array}{c}\text { FEA Angle } \\
\text { of Twist }\end{array}$ & $\begin{array}{c}\text { FEA } \\
\text { Torsional } \\
\text { Rigidity }\end{array}$ & $\begin{array}{l}\text { FEA Avg } \\
\text { Torsional } \\
\text { Rigidity }\end{array}$ \\
\hline 12.5 & 0.34 & \begin{tabular}{|l|}
0.058151 \\
\end{tabular} & 43.53188 & 748.6013 & \multirow{5}{*}{758.6025} & 0.0393 & 1107.681 & \multirow{5}{*}{1107.748} \\
\hline 15.5 & 0.36 & 0.061572 & 53.97953 & 876.6952 & & 0.04873 & 1107.727 & \\
\hline 18.5 & 0.51 & 0.087226 & 64.42718 & 738.6198 & & 0.05816 & 1107.757 & \\
\hline 21.5 & 0.62 & 0.10604 & 74.87483 & 706.0997 & & 0.06759 & 1107.78 & \\
\hline 24.5 & 0.69 & 0.118012 & 85.32248 & 722.9965 & & 0.07702 & 1107.796 & \\
\hline
\end{tabular}

According to Table 1, the value of torsional rigidity is $31.5 \%$ less than that found out by FEA. This is because our notch fixture which was resisting the bending of the chassis only between the front hoop (Point where notch fixture is attached to the chassis) and the rear hard points. The chassis is bending between the front hoop and front bulkhead because of its own weight.

Table 2: Deflection is Measured at a Point Which is between Front Lower Hard points

\begin{tabular}{|c|c|c|c|c|c|c|c|c|}
\hline $\begin{array}{l}\text { Load } \\
(\mathrm{kg})\end{array}$ & $\begin{array}{l}\text { Deflection } \\
\quad(\mathbf{m m})\end{array}$ & $\begin{array}{c}\text { Angle of } \\
\text { Twist } \\
\text { Taking } \\
\text { L=355mm } \\
\text { (degrees) }\end{array}$ & $\begin{array}{c}\text { Toque } \\
\text { Applied } \\
\text { (Nm) }\end{array}$ & $\begin{array}{l}\text { Torsional } \\
\text { Rigidity } \\
\text { (Nm/deg) }\end{array}$ & $\begin{array}{c}\text { Average } \\
\text { Torsional } \\
\text { Rigidity } \\
(\mathbf{N m} / \mathbf{m m})\end{array}$ & $\begin{array}{c}\text { FEA Angle } \\
\text { of Twist }\end{array}$ & $\begin{array}{c}\text { FEA } \\
\text { Torsional } \\
\text { Rigidity }\end{array}$ & $\begin{array}{c}\text { FEA Avg } \\
\text { Torsional } \\
\text { Rigidity }\end{array}$ \\
\hline 12.5 & 0.31 & 0.05302 & 43.53188 & 821.0466 & \multirow{5}{*}{840.2017} & 0.03989 & 1091.298 & \multirow{5}{*}{1091.318} \\
\hline 15.5 & 0.39 & 0.066703 & 53.97953 & 809.2571 & & 0.04946 & 1091.377 & \\
\hline 18.5 & 0.45 & 0.076965 & 64.42718 & 837.1025 & & 0.05904 & 1091.246 & \\
\hline 21.5 & 0.51 & 0.087226 & 74.87483 & 858.3959 & & 0.06861 & 1091.311 & \\
\hline 24.5 & 0.57 & 0.097488 & 85.32248 & 875.2065 & & 0.07818 & 1091.359 & \\
\hline
\end{tabular}

According to Table 2, the value of torsional rigidity is $23 \%$ less than that found out by FEA. This is because placing the notch fixture with $100 \%$ accuracy and a perfectly rigid fixing of the rear is not possible in real life.

Table 3: Deflection is Measured at a Point Which is in Between of the Cockpit

\begin{tabular}{|c|c|c|c|c|c|c|c|c|}
\hline $\begin{array}{c}\text { Load } \\
(\mathrm{kg})\end{array}$ & $\begin{array}{c}\text { Deflection } \\
\text { (mm) }\end{array}$ & $\begin{array}{c}\text { Angle of } \\
\text { Twist Taking } \\
\text { L=355mm } \\
\text { (degrees) }\end{array}$ & $\begin{array}{c}\text { Toque } \\
\text { Applied } \\
\text { (Nm) }\end{array}$ & $\begin{array}{c}\text { Torsional } \\
\text { Rigidity } \\
\text { (Nm/deg) }\end{array}$ & $\begin{array}{c}\text { Average } \\
\text { Torsional } \\
\text { Rigidity } \\
(\mathrm{Nm} / \mathrm{mm})\end{array}$ & $\begin{array}{c}\text { FEA } \\
\text { Angle of } \\
\text { Twist }\end{array}$ & $\begin{array}{c}\text { FEA } \\
\text { Torsional } \\
\text { Rigidity }\end{array}$ & $\begin{array}{c}\text { FEA Avg } \\
\text { Torsional } \\
\text { Rigidity }\end{array}$ \\
\hline 12.5 & 0.09 & 0.015393 & 43.53188 & 2828.05 & \multirow{5}{*}{2709.13} & 0.01285 & 3387.695 & \multirow{5}{*}{3388.373} \\
\hline 15.5 & 0.11 & 0.018814 & 53.97953 & 2869.185 & & 0.01593 & 3388.545 & \\
\hline 18.5 & 0.13 & 0.022234 & 64.42718 & 2897.663 & & 0.01901 & 3389.12 & \\
\hline 21.5 & 0.17 & 0.029075 & 74.87483 & 2575.189 & & 0.0221 & 3388.001 & \\
\hline 24.5 & 0.21 & 0.035917 & 85.32248 & 2375.562 & & 0.02518 & 3388.502 & \\
\hline
\end{tabular}

According to Table 3, the value of torsional rigidity is $20 \%$ less than that found out by FEA. This experimental value deviates minimum from the FEA value because the point at which the measurement was taken is farthest from our jig fixture and notch fixture so errors are less. 
Table 4: Deflection is Measured is Below the Main Hoop

\begin{tabular}{|c|c|c|c|c|c|c|c|c|}
\hline $\begin{array}{c}\text { Load } \\
\text { (kg) }\end{array}$ & $\begin{array}{c}\text { Deflection } \\
(\mathrm{mm})\end{array}$ & $\begin{array}{c}\text { Angle of } \\
\text { Twist Taking } \\
\text { L=355mm } \\
\text { (degrees) }\end{array}$ & $\begin{array}{c}\text { Toque } \\
\text { Applied } \\
(\mathbf{N m})\end{array}$ & $\begin{array}{c}\text { Torsional } \\
\text { Rigidity } \\
\text { (Nm/deg) }\end{array}$ & \begin{tabular}{|c|} 
Average \\
Torsional \\
Rigidity \\
$(\mathbf{N m} / \mathbf{m m})$
\end{tabular} & $\begin{array}{c}\text { FEA Angle } \\
\text { of Twist }\end{array}$ & \begin{tabular}{|c} 
FEA \\
Torsional \\
Rigidity
\end{tabular} & $\begin{array}{l}\text { FEA Avg } \\
\text { Torsional } \\
\text { Rigidity }\end{array}$ \\
\hline 12.5 & 0.05 & 0.008552 & 43.53188 & 5090.489 & \multirow{5}{*}{4265.58} & 0.003894 & 11179.22 & \multirow{5}{*}{11180.11} \\
\hline 15.5 & 0.07 & 0.011972 & 53.97953 & 4508.719 & & 0.004828 & 11180.51 & \\
\hline 18.5 & 0.09 & 0.015393 & 64.42718 & 4185.514 & & 0.005763 & 11179.45 & \\
\hline 21.5 & 0.11 & 0.018814 & 74.87483 & 3979.837 & & 0.006697 & 11180.35 & \\
\hline 24.5 & 0.14 & 0.023945 & 85.32248 & 3563.343 & & 0.007631 & 11181.03 & \\
\hline
\end{tabular}

According to Table 4, the value of torsional rigidity is $61.8 \%$ less than that found out by FEA. This experimental value deviates most from the FEA value because in FEA we had fixed the rear hard points but in real life the rear hard points will still have some rotational movement because of torsion and as there will be small gaps between the plates of the jig fixtures, deflection would be more and thus torsional rigidity will be less.

\section{CONCLUSIONS}

- The torsional rigidity of space frame chassis was found using FEA and verified using experimental testing. It was found that the experimental value of torsional rigidity was lesser than that computed by FEA because of errors in manufacturing and the welded joints are weaker than the plain tube and as FEA does not consider these values.

- As we move away from the point of load application towards the fixture the torsional rigidity increases as the angle of twist decreases.

- The experimental value of torsional rigidity near the jig fixture deviates more from FEA because it is impossible to fix the rear part completely so in the experiment the rear part which was supposed to be fixed was rotating so the angle of twist increases and the torsional rigidity decreases.

- Advancement in design is needed to eliminate errors in the experiment by making the rear hard points more rigid. This experiment can also be done in a reverse way by fixing the front hard points and applying torque from the front.

- Overall Torsional Rigidity of the car is $\frac{1}{K}=\frac{1}{\mathrm{k}(\text { Front })}+\frac{1}{\mathrm{k} \text { (Cockpit) }}+\frac{1}{\mathrm{k}(\text { Rear })}$

$\frac{1}{K}=\frac{1}{758.60}+\frac{1}{2709.13}+\frac{1}{4265}$

So, $\mathrm{K}_{\text {overall }}=520.348 \mathrm{Nm} / \mathrm{deg}$

\section{ACKNOWLEDGEMENTS}

Authors are grateful to VIT - Chennai for providing us with resources to carry out the experiment. We are also thankful to our team Shaurya Racing for giving us an opportunity to do validation of torsional rigidity. 


\section{REFERENCES}

1. Edmund et al. 1997. Introduction to formula SAE suspension and frame design. SAE international.

2. 2018 Formula Bharat rulebook.

3. C. A. Featherston et al. 2005. Measuring the torsional stiffness of spaceframe chassis using 3D motion capturing technique. Researchgate.

4. William B. Riley. 2002. Design, Analysis and testing of Formula SAE car chassis design. SAE International.

5. Tanawat Limwathanagura et al. 2012. The frame analysis and testing for student formula. International journal of mechanical and mechatronics engineering.

6. Panf Shu-yi et al. 2010. Research on chassis torsional stiffness on vehicle handling performance. IEEE computer society Washington.

7. Tomar, A., \& Singh, D. Static Analysis, Modal Analysis And Design Modification In Chassis Frame To Optimize Weight By Using Composite Material. International Journal of Mechanical Engineering (IJME), ISSN (P), 2319-2240.

8. Yu Wang et al. 2016. Research on optimisation of Formula SAE truss frame. ICMME.

9. Amy Elizabeth Chambers et al. 2016. Development of a test stand for determining the torsional rigidity of SAE spaceframe chassis. American Society for Engineering Education.

10. Hubbard D. Velie. Chassis torsional rigidity analysis for Formula SAE racecar.

11. William F. et al. 1995. Race car Vehicle Dynamics. Society of automotive engineering. 
